\title{
The diagnostic value and functional roles of phosphoglycerate mutase 1 in glioma
}

\author{
ZHENKUAN XU ${ }^{1}$, JIE GONG $^{1}$, CHUANWEI WANG $^{1}$, YUNYAN WANG $^{1}$, \\ YAN SONG ${ }^{1}$, WENZHE XU ${ }^{1}$, ZHIGUO LIU ${ }^{2}$ and YUGUANG LIU ${ }^{1}$ \\ ${ }^{1}$ Department of Neurosurgery, Qilu Hospital of Shandong University, Brain Science Research Institute of Shandong University; \\ ${ }^{2}$ Department of Neurosurgery, Shandong Provincial Hospital Affiliated to Shandong University, Shandong Cancer Hospital, \\ Shandong Provincial Institute of Cancer Prevention and Treatment, Jinan, Shandong 250012, P.R. China
}

Received April 4, 2016; Accepted August 1, 2016

DOI: $10.3892 /$ or.2016.5046

\begin{abstract}
Previous studies indicated that phosphoglycerate mutase 1 (PGAM1) is involved in many cancer types and promotes breast cancer progression. However, the role of PGAM1 in glioma remains unclear. The present study aimed to investigate the association of PGAM1 expression with glioma grade and the role of PGAM1 in proliferation, apoptosis, migration and invasion of glioma cells. The mRNA and protein expression of PGAM1 was analysed in glioma tissues and normal brain tissues. The expression of PGAM1 was examined further by immunohistochemical analysis. In addition, we inhibited the expression of PGAM1 in glioma cell line by siRNA to evaluate its role in glioma proliferation, apoptosis, migration and invasion. The mRNA and protein expression of PGAM1 was significantly greater in glioma than normal brain tissues. PGAM1 expression was associated with the WHO grade of glioma. siRNA knockdown of PGAM1 significantly inhibited glioma cell proliferation, promoted glioma cell apoptosis, induced $\mathrm{S}$ phase cell cycle arrest and inhibited glioma cell migration and invasion in vitro. PGAM1 may be associated with the grade of glioma and be involved in the biological behavior of glioma cells. PGAM1 might be a novel therapeutic target in glioma.
\end{abstract}

Correspondence to: Dr Zhiguo Liu, Department of Neurosurgery, Shandong Provincial Hospital Affiliated to Shandong University, Shandong Cancer Hospital, Shandong Provincial Institute of Cancer Prevention and Treatment, Jinan, Shandong 250012, P.R. China E-mail: Lzg05211@163.com

Dr Yuguang Liu, Department of Neurosurgery, Qilu Hospital of Shandong University, Brain Science Research Institute of Shandong University, Jinan, Shandong 250012, P.R. China

E-mail: NS3000@126.com

Key words: phosphoglycerate mutase 1, glioma, proliferation, migration, invasion, apoptosis

\section{Introduction}

Gliomas are the most common primary brain tumors and account for 40-50\% of primary intracranial neoplasms (1). They can occur anywhere in the central nervous system but primarily in the brain, and originate from abnormally proliferating glial cells, which normally supply nutrition and protection to neurons in the central nervous system (2). The etiology and pathogenesis of gliomas still remain obscure. Despite the advances in therapeutic approaches, the treatment offers limited help to prolong survival (3). In view of the overall poor outcome with current therapies, a better understanding of glioma etiology is crucial for future development of more effective treatments to cure this rapidly progressing disease.

Phosphoglycerate mutase 1 (PGAM1) catalyzes the conversion of 3-phosphoglycerate (3-PG) to 2-phosphoglycerate (2-PG) to release energy during glycolysis. Proteome reactivity profiling was used to determine the drug target against breast cancer, and PGAM1 was found a potential metabolic enzyme participating in breast carcinogenesis (4). Several studies demonstrated that PGAM1 activity was increased in a variety of human cancers, including lung (5), breast (4), prostate cancer (6), hepatocellular carcinoma (7), colorectal cancer (8), oral squamous cell carcinoma (9), and esophageal squamous cell carcinoma (10) and also associated with virus infection (11) and spermatogenic dysfunction (12). Previous reports have described that targeting PGAM1 by a PGAM1derived inhibitory peptide or PGAM inhibitor MJE3 could attenuate breast cancer cell proliferation $(4,13)$. However, the association of PGAM1 with glioma grade and the role of PGAM1 in glioma are poorly investigated.

In the present study, we aimed to evaluate the expression patterns, the clinical roles and the functions of PGAM1 in human gliomas, as a possible diagnostic biomarker and therapeutic target for glioma.

\section{Materials and methods}

Patients and tissue specimens. All 124 glioma specimens were obtained from patients with primary glioma who underwent surgical treatment between July 2012 and May 2014 at Qilu Hospital; 20 normal brain tissue samples were collected from 
patients undergoing surgery for epilepsy and were reviewed to verify the absence of a tumor. For all patients, the histological types and grade of gliomas were evaluated by two experienced pathologists according to the 2007 WHO Classification of Tumors of the Central Nervous System (14). All patients had a well-documented clinical history. The study protocol was approved by the Ethics Committee of Qilu Hospital (Shandong, China). Informed consent was obtained from all patients included in the study.

RNA isolation and real-time PCR. Total RNA was extracted from frozen specimens by using TRIzol reagent (Invitrogen/ Life Technologies, Carlsbad, CA, USA) according to the manufacturer's instructions. cDNA was generated by reverse transcription of $1 \mu \mathrm{g}$ total RNA with primer oligonucleotides. qPCR reactions were conducted in a $10-\mu 1$ reaction volume with SYBR-Green I, with a 1:25 dilution of the cDNA and $20 \mathrm{nM}$ primers. $\beta$-actin was a reference gene. The primers were designed by the use of Primer Premier 5.0 (Premier Biosoft International, Palo Alto, CA, USA) from mRNA sequences in the GenBank database. Primer sequences were for PGAM1 (sense: 5'-GTGCAGAAGAGAGCGATCCG-3' and antisense: 5'-CGGTTAGACCCCCATAGTGC-3'); $\beta$-actin (sense: 5'-CGTTGACATCCGTAAAGACC-3' and antisense: 5'-TAGAGCCACCAATCCACACA-3'). Calculation of PGAM1 mRNA levels was based on cycle threshold $(\mathrm{Ct})$ values and determined by relative quantification with $\beta$-actin as a normalizing gene according to the following equation: $2^{-\Delta \mathrm{Ct}}[\Delta \mathrm{Ct}=\mathrm{Ct}(\mathrm{PGAM})-\mathrm{Ct}(\beta$-actin $)]$. All experiments were performed in triplicate.

Western blot analysis. Briefly, cultured cells and tissues were lysed in RIPA buffer (Beyotime Institute of Biotechnology, Haimen, China) containing $50 \mathrm{mM}$ Tris (pH 7.4), $150 \mathrm{mM}$ $\mathrm{NaCl}, 1 \%$ Triton $\mathrm{X}-100,1 \%$ sodium deoxycholate, $0.1 \%$ SDS and protease inhibitor cocktail with $1 \mathrm{mM}$ phenylmethanesulfonyl fluoride (Beyotime Institute of Biotechnology). Lysates were centrifuged at $12,000 \mathrm{x}$ g for $15 \mathrm{~min}$ and the protein concentration of the supernatant was quantified by the BCA method. An amount of $20 \mu \mathrm{g}$ protein from each sample was separated by $10 \%$ SDS-PAGE and transferred to a polyvinylidene difluoride membranes. After blocking with 5\% non-fat milk in phosphate-buffered saline (PBS) Tween-20 for $1 \mathrm{~h}$ at room temperature, the membranes were incubated with primary antibody overnight. The membrane was rinsed and washed 3 times with TBS containing $0.1 \%$ Tween-20, then incubated with horseradish peroxidase-conjugated secondary antibody for $2 \mathrm{~h}$ at room temperature. Immunoreactive bands were visualized by using the Immobilon Western Chemiluminescent HRP Substrate kit (Millipore). Immunoreactive labeling was analyzed by the use of ImageJ 1.44 (National Institutes of Health, Bethesda, MD, USA) and standardized against $\beta$-actin protein level.

Antibody for PGAM1 was from Santa Cruz Biotechnology (Dallas, TX, USA); antibodies for Bax, Bcl-2, matrix metalloproteinase 2 (MMP2)/9 and cleaved caspase-3 were from Cell Signaling Technology (Danvers, MA, USA).

Immunohistochemistry. All samples were fixed with $10 \%$ buffered formalin and embedded in paraffin. Slices of paraffin tissues were cut as $4-\mu \mathrm{m}$ serial sections. Slides were stained according to the manufacturer's protocol. In brief, slides were deparaffinized by using xylene and rehydrated through an ethanol series to water. The dewaxed slides underwent antigen retrieval in citrate buffer for $30 \mathrm{~min}$ by microwaving and then cooled to room temperature to expose antigen epitopes. An amount of $3 \%$ hydrogen peroxide was added to slides to inhibit endogenous peroxidase activity. The slides were blocked with $10 \%$ normal goat serum for $1 \mathrm{~h}$ at $37^{\circ} \mathrm{C}$, then incubated with primary rabbit anti-human PGAM1 polyclonal antibody overnight at $4^{\circ} \mathrm{C}$, then anti-rabbit secondary antibody. Finally, DAB was used as chromogen, and the slides were counterstained with hematoxylin. Slides were dehydrated and mounted with neutral balsam according to the laboratory protocol. Staining with PBS instead of the primary antibody was a negative control.

Evaluation of immunohistochemistry. Each stained slide was simultaneously scored by two independent pathologists who were blinded to the clinical information. We selected 10 low-power fields randomly, and counted cells at high-power field. The percentage of PGAM1-positive cells was scored as 4 categories: 0 , no staining; $1,<25 \%$ cells; $2,25-75 \%$ cells; and $3,>75 \%$ cells. The intensity of positive staining was scored as 4 grades: 0, negative; 1 , weak; 2 , moderate; and 3, strong. The final staining score was then obtained (ranging from 0 to 9) by the multiplication of the intensity and percentage scores. The staining pattern of slides was scored as $0,-; 1-3,+; 4-6,++$; and $6-9,+++$. In addition, samples with scores up to ++ were considered positive.

Cell culture. The human glioma cell line (U87) was obtained from the Chinese Academy of Science and cultured in Dulbecco's modified Eagle's medium (DMEM) supplemented with $10 \%$ fetal bovine serum (FBS), $100 \mathrm{U} / \mathrm{ml}$ penicillin, and $100 \mu \mathrm{g} / \mathrm{ml}$ streptomycin at $37^{\circ} \mathrm{C}$ in a humidified atmosphere containing $5 \% \mathrm{CO}_{2}$ in $60-\mathrm{mm}$ flasks.

Transfection. When cultured U87 cells reached 90\% confluence, they were transfected with siRNA targeting PGAM1. The siRNA sequences were as follows: PGAM1-siRNA: 5'-CG ACUGGUAUUCCCAUUGUTT-3' and 5'-ACAAUGGGAA UACCAGUCGTT-3'; Negative scramble control sequences: 5'-UUCUCCGAACGUGUCACGUTT-3' and 5'-ACGUGAC ACGUUCGGAGAATT-3'. The RNA duplexes were synthesized by Shanghai GenePharma Co., Ltd. (Shanghai, China). Transfection of siRNA involved use of Lipofectamine 2000 (Invitrogen/Life Technologies) according to the manufacturer's instructions. The efficiency of gene silencing was confirmed by assaying PGAM1 protein levels.

Cell proliferation assay. Proliferation of U87 cells was determined by standard MTT assay (Beyotime Institute of Biotechnology). Briefly, MTT solution $(20 \mu 1,5 \mathrm{mg} / \mathrm{ml})$ was added into each well for incubation at $37^{\circ} \mathrm{C}$ for $4 \mathrm{~h}$. Then the solution was removed by aspiration, the insoluble formazan crystals were dissolved in $150 \mu \mathrm{l} /$ well dimethyl sulfoxide (DMSO), and absorbance at $490 \mathrm{~nm}$ was measured by the use of a Varioskan Flash spectral scanning multimode reader (Thermo Electron Oy, Vantaa, Finland). The spectrophoto- 
meter was calibrated to zero absorbance with culture medium without cells. The percentage of cell survival was determined by comparing the average absorbance of treated cells to that of untreated cells. The experiment was repeated at least 3 times.

Cell apoptosis analysis. Cell apoptosis was evaluated by the use of an Annexin V-FITC/PI kit (Invitrogen/Life Technologies). Briefly, after treatment, attached cells were collected and washed with PBS twice. An amount of $400 \mu$ l binding buffer, $5 \mu 1$ Annexin V FITC and $5 \mu 1$ PI was successively added to the cell suspension. After 15 min of incubation in the dark, cells underwent flow cytometry (Becton-Dickinson, San Jose, CA, USA). At least 3 independent experiments were carried out.

Cell cycle analysis. Cell cycle analysis was evaluated with a PI staining kit (Beyotime Institute of Biotechnology). Briefly, $\sim 12 \times 10^{5}$ U87 cells were seeded in a 6-well plate, allowed to attach for $48 \mathrm{~h}$, then cells were collected by the trypsin method, washed with PBS, and fixed overnight at $4^{\circ} \mathrm{C}$ in $70 \%$ ethanol. Fixed cells were washed with PBS; $20 \mu 1$ RNase A was added and incubated at $37^{\circ} \mathrm{C}$ for $30 \mathrm{~min}$ to hydrolyze RNA, then cells were stained with PI in the dark for another $30 \mathrm{~min}$, and the cell cycle was evaluated by flow cytometry. The experiments were repeated at least 3 times independently.

In vitro cell migration and invasion Boyden chamber assay with some modifications. Briefly, $5 \times 10^{4}$ siRNA-transfected cells in $0.1 \mathrm{ml}$ of serum-free DMEM were added to the wells of an 8- $\mu \mathrm{m}$ pore membrane Boyden chamber (Corning, Inc., Corning, NY, USA) uncoated (for the migration assay) or coated with Matrigel (BD Biosciences; for the invasion assay). The bottom chamber contained 10\% FBS in DMEM, which served as a chemoattractant. Cells were allowed to invade for $48 \mathrm{~h}$, and the cells that had not penetrated the filters were removed from the filters with cotton swabs. Chambers were fixed for $20 \mathrm{~min}$ at room temperature with $4 \%$ formaldehyde in PBS, stained in $0.1 \%$ crystal violet for $30 \mathrm{~min}$, and rinsed in water. Cells that migrated to the bottom surface of the filter were counted under a light microscope. Assays were performed 3 times with triplicate wells.

Statistical analysis. Data are expressed as mean \pm SEM. SPSS 18.0 was used for analysis. Data were analyzed by two-tailed Student's t-test and one-way ANOVA. Chi-square test was used to analyze categorical data. $\mathrm{P}<0.05$ was considered statistically significant.

\section{Results}

PGAM1 is upregulated in human glioma tissues. Expression of PGAM1 was compared at both transcriptional and translational levels between glioma tissues and normal brain tissues. We analyzed the mRNA expression of PGAM1 in glioma tissues and normal brain tissues to assess the role of PGAM1 in the malignant progression of glioma. PGAM1 mRNA level was higher in low-grade and high-grade glioma than normal brain tissue (Fig. 1A) and PGAM1 protein expression was higher in tumor tissue (Fig. 1B). Immunohistochemical staining was used to detect the expression of PGAM1 in paraffin-embedded
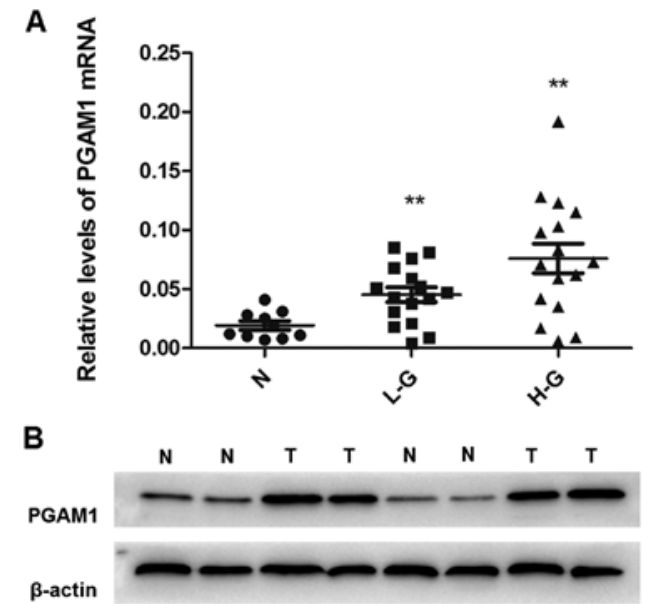

Figure 1. Expression of PGAM1 in normal brain tissues and glioma tissues. (A) RT-PCR analysis of PGAM1 mRNA levels in glioma and normal brain tissue. (B) Western blot analysis of PGAM1 protein expression in glioma and normal brain tissues. Data are mean \pm SD of 3 independent experiments. $\left({ }^{* *} \mathrm{P}<0.01\right)$. N, normal brain tissue; L-G, low-grade glioma; $\mathrm{H}-\mathrm{G}$, high-grade glioma; T, glioma. Each data point represents one sample.

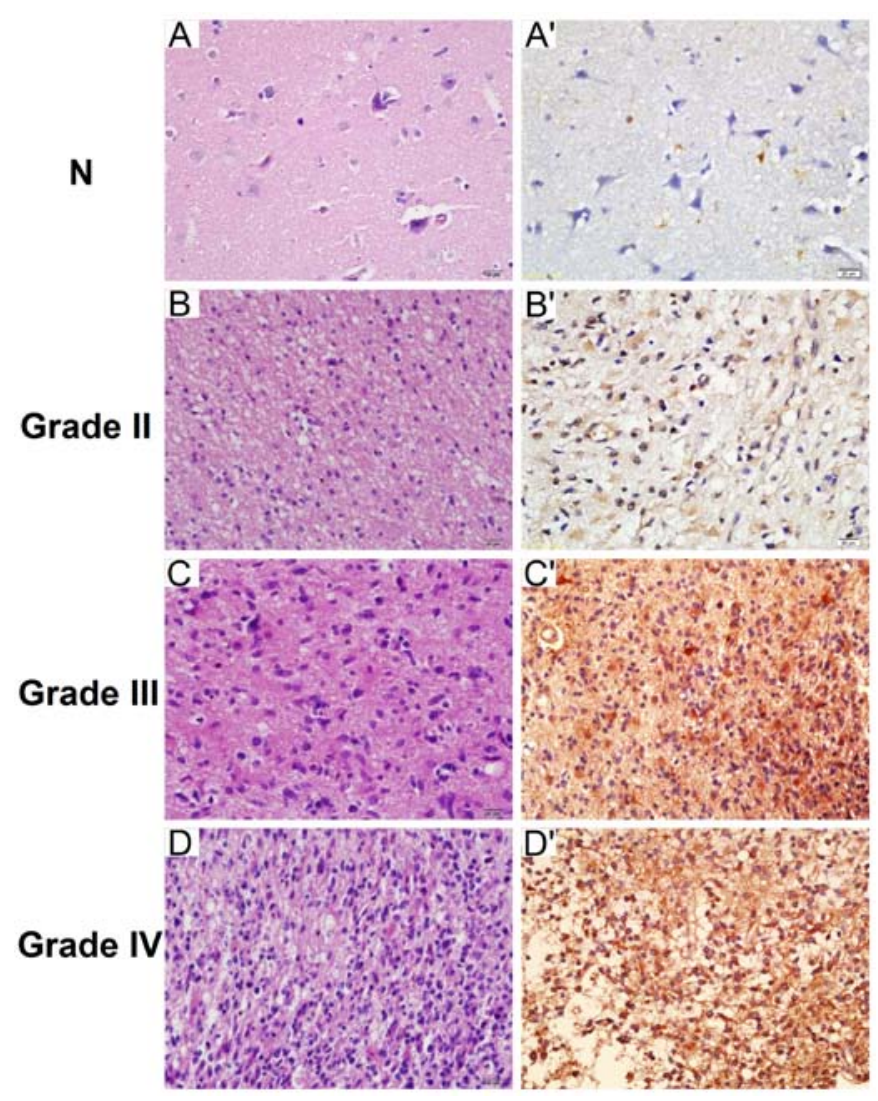

Figure 2. Immunohistochemical staining patterns of PGAM1 in normal brain tissue and grades of glioma tissue. Scale bar, $20 \mu \mathrm{m}$.

tissues (Fig. 2). PGAM1 was predominantly confined to the cytoplasm of tumor cells. PGAM1-positive expression was present in $74.2 \%$ (92/124) of glioma tissues and in 25\% (5/20) of normal brain tissues (Table I).

The protein expression of PGAM1 in tissue by glioma grade. PGAM1 protein expression was associated with glioma grade 
Table I. PGAM1 expression in glioma tissues and normal brain tissues.

\begin{tabular}{lrlcr}
\hline Tissues & Total & \multicolumn{1}{c}{$-+(\%)$} & $++/+++(\%)$ & P-value \\
\hline Normal & 20 & $15(75)$ & $5(25)$ & \\
Glioma & 124 & $32(25.8)$ & $92(74.2)$ & $<0.05$ \\
\hline
\end{tabular}
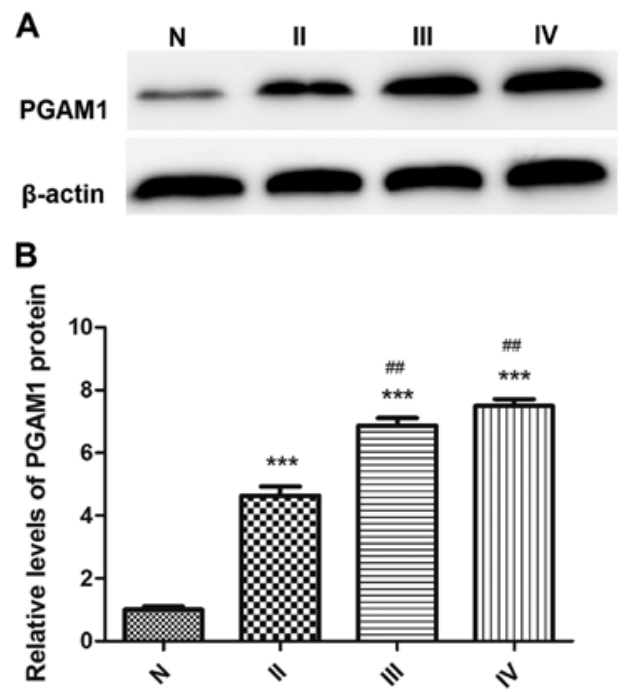

Figure 3. Expression of PGAM1 in different grades of glioma tissues. (A and B) Western blot analysis of PGAM1 protein expression by glioma grade. Data are mean $\pm \mathrm{SD}$ of 3 independent experiments. ${ }^{* * * *} \mathrm{P}<0.001$ compared with control; ${ }^{\# \#} \mathrm{P}<0.01$ compared with II).
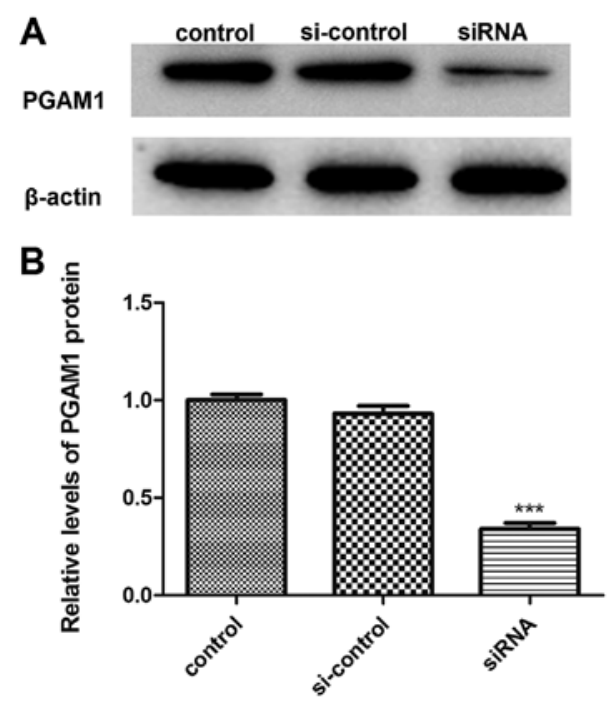

Figure 4. Transfection efficiency of PGAM1 siRNA in U87 cells. The downregulation of PGAM1 was confirmed by western blot analysis. Data are mean \pm SD of 3 independent experiments. $\left({ }^{* * *} \mathrm{P}<0.001\right.$ compared with si-control).

(Fig. 3). The expression of PGAM1 was $56.3 \%$ in grade II glioma, $79.0 \%$ in grade III glioma and $81.5 \%$ in grade IV glioma on immunohistochemistry (Table II). PGAM1 protein expression was higher in high-grade glioma than low-grade

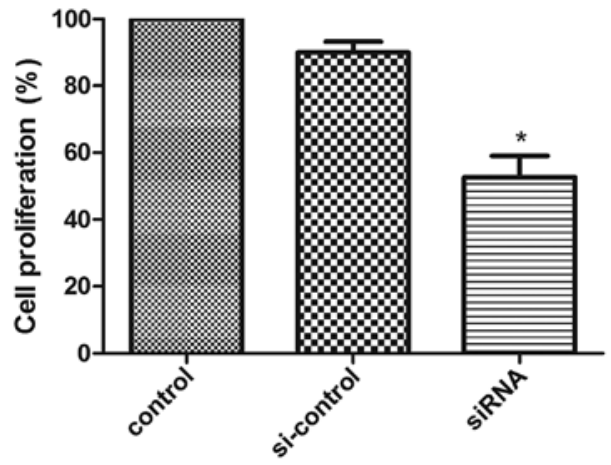

Figure 5. Evaluation of proliferation of U87 cells. MTT assays of proliferation of U87 cells transfected with PGAM1 siRNA at $48 \mathrm{~h}$. ("P<0.05 compared with si-control).

Table II. Association between PGAM1 protein level and clinicopathological features of glioma patients.

\begin{tabular}{lcccc}
\hline Variables & Total & $-/+(\%)$ & $++/+++(\%)$ & P-value \\
\hline $\begin{array}{l}\text { Age (years) } \\
<50\end{array}$ & 67 & $36(53.7)$ & $31(46.3)$ & \\
$\geq 50$ & 57 & $29(50.9)$ & $28(49.1)$ & $0.751>0.05$ \\
Gender & & & & \\
$\quad$ Male & 69 & $35(50.7)$ & $34(49.3)$ & \\
Female & 55 & $30(54.6)$ & $25(45.4)$ & $0.672>0.05$ \\
WHO grade & & & & \\
II & 32 & $14(43.7)$ & $18(56.3)$ & \\
III & 38 & $8(21.0)$ & $30(79.0)$ & $<0.05$ III vs. II \\
IV & 54 & $10(18.5)$ & $44(81.5)$ & $<0.05$ IV vs. II \\
\end{tabular}

glioma tissue. The significant upregulation of PGAM1 in glioma tissues indicated that PGAM1 may function as a tumor promoter in glioma.

Downregulation of PGAM1 inhibits glioma cell proliferation in vitro. We transiently transfected PGAM1 siRNA into U87 glioma cells to investigate the potential function of PGAM1 and confirmed the downregulation of PGAM1 protein level with PGAM1 siRNA transfection as compared with controls (Fig. 4). Cell proliferation ability was analyzed by MTT assay at $48 \mathrm{~h}$ after transfection in U87 cells. Cell proliferation was reduced with PGAM1 siRNA transfection as compared with negative control transfection in U87 cells (Fig. 5). Therefore, downregulation of PGAM1 inhibited glioma cell growth in vitro.

Knockdown of PGAM1 induces apoptosis in U87 cells. Cell apoptosis was measured by Annexin V FITC/PI staining to further explore the mechanism of PGAM1 modulating glioma cell growth (Fig. 6A). siRNA knockdown of PGAM1 significantly increased cell apoptosis as compared with controls. After transfection for $48 \mathrm{~h}$, the early apoptotic cells (right lower domain of the fluorocytogram) and late apoptotic cells (right upper domain of the fluorocytogram) increased 
A

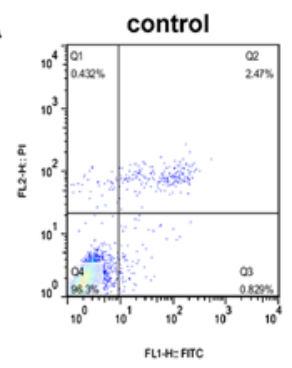

B

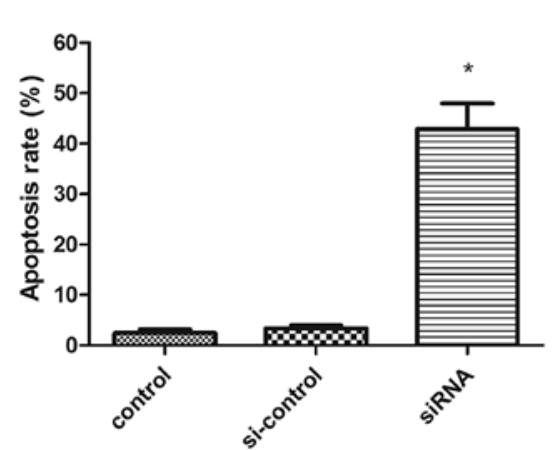

D

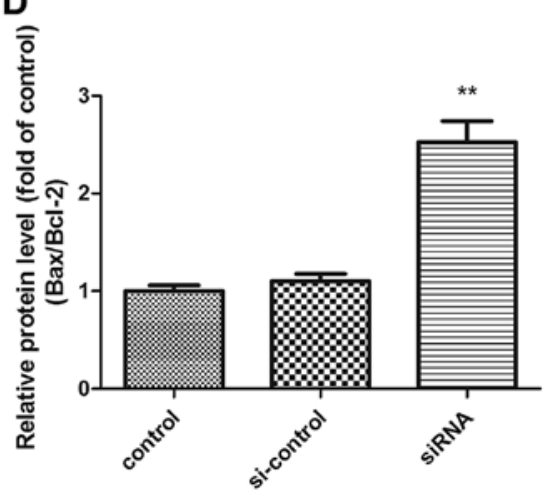

si-control

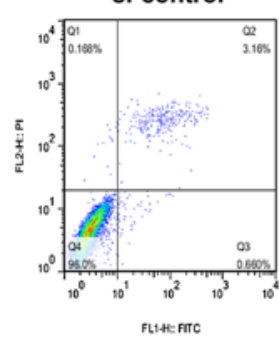

C

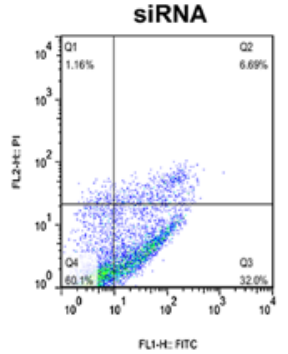

Fu.HE FitC

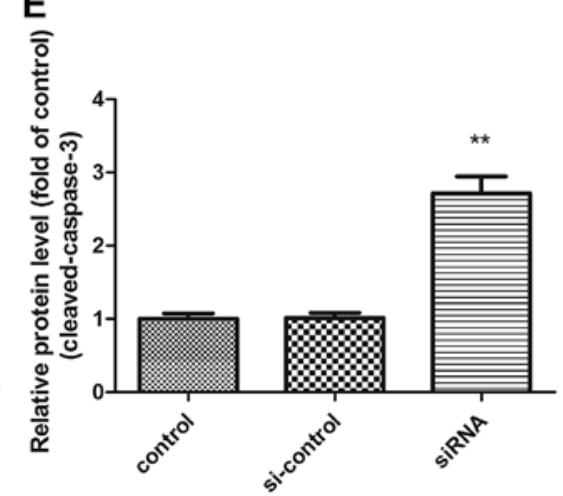

Figure 6. Evaluation of apoptosis rate of U87 cells. (A and B) Flow cytometry of the proportion of apoptotic cells. Western blot analysis of the effect of PGAM1 siRNA on apoptosis markers (C), ratio of Bax to Bcl-2 expression (D), and protein expression of cleaved caspase-3 (E) in U87 cells, with $\beta$-actin as an internal control. Data are mean \pm SD of 3 independent experiments. ("P $<0.05$ compared with si-control; ${ }^{* *} \mathrm{P}<0.01$ compared with si-control).

from $0.83 \pm 0.67$ and $2.47 \pm 0.39$ to $32.0 \pm 4.26$ and $6.69 \pm 3.11 \%$, respectively; thus, the total mean apoptotic rate reached $42.9 \%$ with PGAM1 siRNA transfection (Fig. 6B). Apoptosis regulators were further examined (Fig. 6C). The ratio of Bax to Bcl-2 expression increased in U87 cells with PGAM1 siRNA knockdown (Fig. 6D). Additionally, cleaved caspase-3 activity was significantly upregulated in PGAM1 siRNA-transfected glioma cells compared with the control (Fig. 6E).

Silencing of PGAM1 induces cell cycle arrest in U87 cells. Knockdown of PGAM1 significantly increased the cell population in the $\mathrm{S}$ phase and decreased that in the $\mathrm{G} 2 / \mathrm{M}$ phase (Fig. 7A). The controls had a mean of $13.48 \pm 2.03 \%$ cells in the $\mathrm{S}$ phase; after siRNA transfection for $48 \mathrm{~h}$, the rates increased to $46.86 \pm 2.73 \%$ (Fig. 7C), and the rates of cells in the G2/M phase decreased from $22.16 \pm 0.95$ to $8.61 \pm 0.37 \%$ (Fig. 7B) Therefore, PGAM1 siRNA knockdown induced S-phase cell cycle arrest in U87 cells.
PGAM1 knockdown inhibited glioma cell migration and invasion. To test the effect of PGAM1 on glioma cell mobility, we performed Transwell migration and invasion assays in U87 cells at $48 \mathrm{~h}$ after PGAM1 siRNA transfection. The migration ability of transfected U87 cells was decreased (Fig. 8A and B). Furthermore, the invasion ability of transfected cells was inhibited as compared with controls (Fig. 8A and C). Since MMP2/9 play important roles in tumor cell migration and invasion, we examined the effect of PGAM1 on their expression. PGAM1 siRNA knockdown downregulated MMP2/9 protein levels in U87 cells (Fig. 8D-F). PGAM1 knockdown may significantly inhibit glioma cell migration and invasion in vitro.

\section{Discussion}

Glioma is one of the most common adult primary central nervous system tumors, with a median survival of only 14.6 

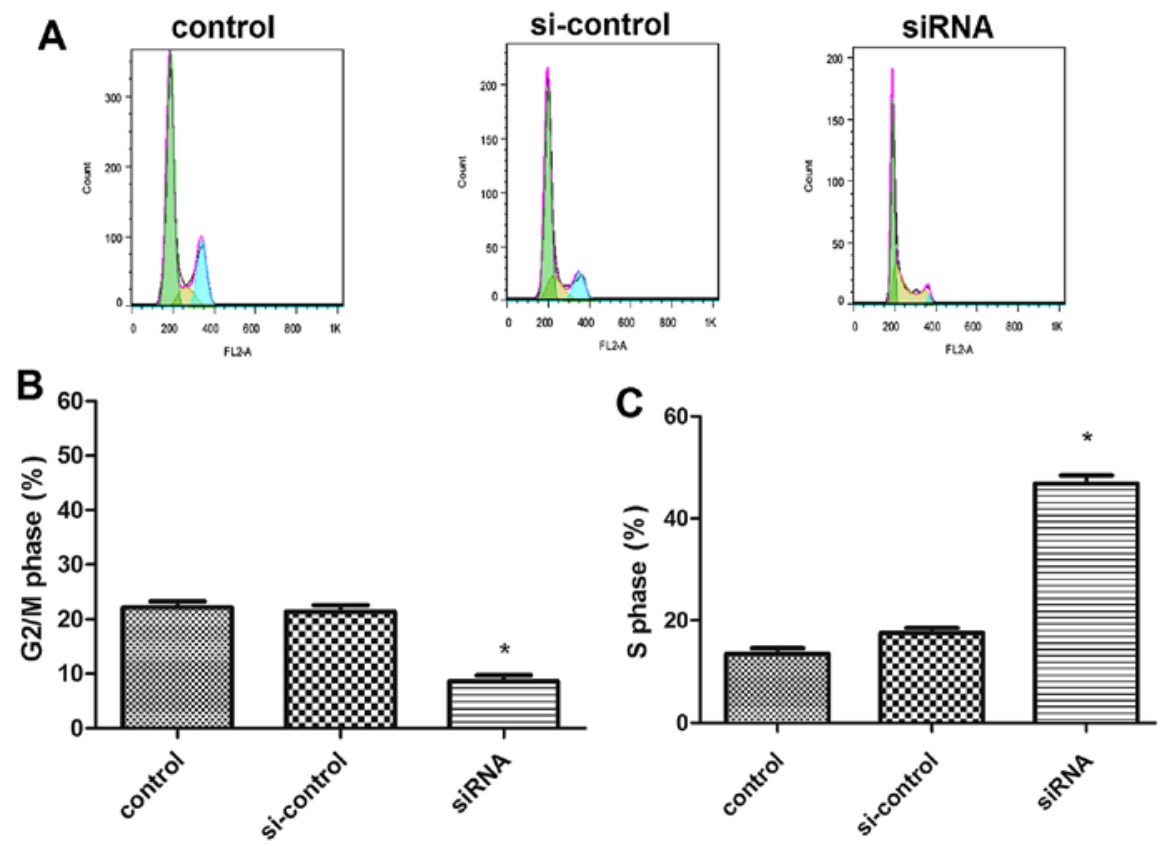

Figure 7. Cell cycle analysis of U87 cells. (A) Flow cytometry of U87 cells stained with PI for cell cycle analysis. G2/M phase rate in PGAM1 siRNAknockdown cells (B), and S phase rate (C). Data are mean \pm SD of 3 independent experiments. ( $\mathrm{P}<0.05$ compared with si-control).

months after diagnosis $(14,15)$. Gliomas can be classified into WHO grades I-IV based on malignant behavior (14). Standard treatment includes surgical operation followed by radiotherapy and chemotherapy (16). Glioma is rarely curable despite these treatments. Since the major barrier to effective treatment of glioma is their highly invasive nature, special attention needs to be paid to the molecular determinants regulating their malignant behavior. In this study, we demonstrated upregulated mRNA and protein levels of PGAM1 in glioma tissues. Importantly, the expression of PGAM1 was significantly associated with WHO grade of glioma. siRNA knockdown of PGAM1 inhibited glioma cell growth, migration and invasion, and induced cell apoptosis and cell cycle arrest. PGAM1 might be a novel therapeutic target in glioma.

The Warburg effect is a property of cancer cells whereby cancer cells maintain a high rate of aerobic glycolysis even under the high-oxygen $(20 \%)$ conditions of normal tissue culture (17). The effect helps cancer cells generate more ATP more quickly than normal cells, which mainly rely on oxidative phosphorylation. As well, tumor tissue accumulates more glucose than does normal tissue, because cancer cells make use of large amounts of glucose as a molecular source for anabolic biosynthesis of macromolecules, which are necessary for cancer cell proliferation (18). The idea that tumors have a particular metabolic phenotype that is associated with increased glycolysis is supported by molecular and functional data (19). Microarray datasets collected from several studies have consistently shown most of the genes involved in glucose transport and glycolysis are upregulated in different types of tumors $(20,21)$. Glucose transporters are overexpressed in hepatocarcinomas, breast cancer, neuroendocrine carcinomas, lymphoblastic leukemia and others (22-25). In mesenchymal glioma stem cells, the glycolysis pathway is highly upregulated, involving aldehydedehydrogenase $1 \mathrm{~A} 3$, which creates heterogeneous cellular populations (26). A recent study demonstrated that the activity of oxidative phosphorylation complexes and citrate synthase was gradually decreased by tumor grade in glioma as compared with normal brain tissue (27). This shift in cellular energy production from oxidative phosphorylation to glycolysis is a result of the glioma adapting to the surrounding environment. Several mechanisms were involved in the downregulation of oxidative phosphorylation in tumor cells. Lack of vascularization in tumors causes severe hypoxia, which leads to a compensatory upregulation of glycolysis in tumors. Genetic inactivation of $p 53$ gene, a regulator of oxidative phosphorylation, or activation of oncogenes can result in a secondary decrease in oxidative phosphorylation (28-31). Loss of function of components of oxidative phosphorylation has been demonstrated in pheochromocytomas and paragangliomas (32). In this context, glycolysis plays a significant role in survival and growth of cancer cells (33). Therefore, intervening in glycolysis could result in remarkable inhibition of cell growth and induction of cell death $(13,34)$.

PGAM1 is involved in the Warburg effect and catalyzes the conversion of 3-PG to 2-PG, a crucial step in glycolysis (35). PGAM1 controls intracellular 3-PG and 2-PG levels and is important for anabolic biosynthesis in cells. PGAM1 knockdown increases 3-PG level and reduces 2-PG level. PGAM1 enzyme activity strikes a balance between 3-PG and 2-PG levels, which coordinates glycolysis and biosynthesis to promote cancer cell proliferation (36).

PGAM1 activity is upregulated in many cancers. Targeting PGAM1 by a small molecule inhibitor inhibited cancer cell proliferation and tumor growth and altered 3-PG and 2-PG levels in primary leukemia cells from human patients, thereby leading to attenuated leukemia cell proliferation $(4,13,36)$. A recent study revealed that Y26 phosphorylation of PGAM1 enhanced PGAM1 activity by stabilising the active conformation of PGAM1, which promoted tumor growth (37). Protein expression profile analysis revealed that overexpression of 


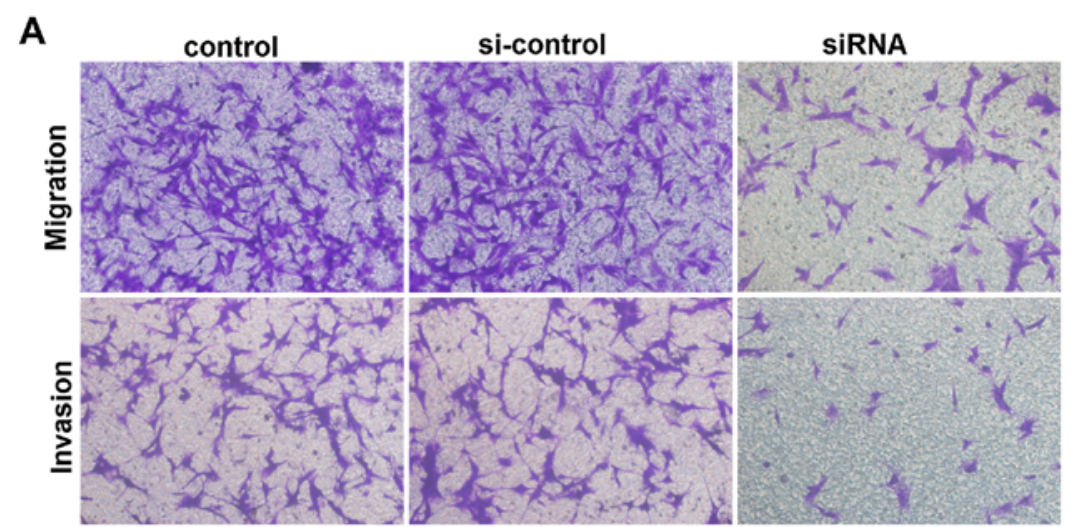

B
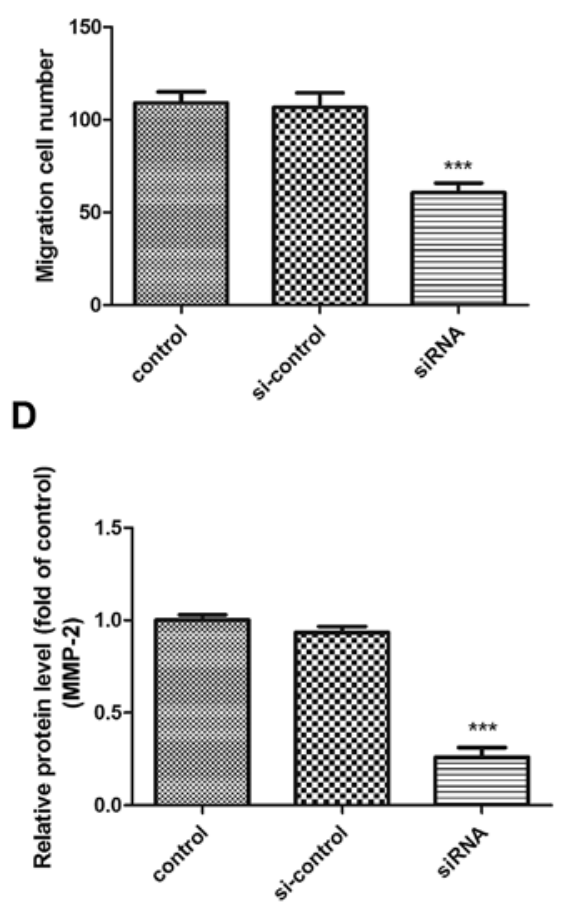

C

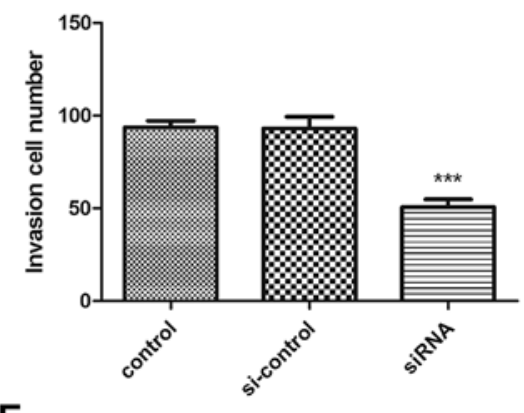

$\mathbf{E}$

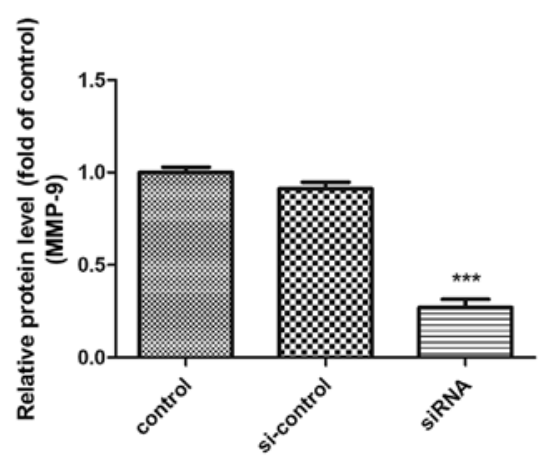

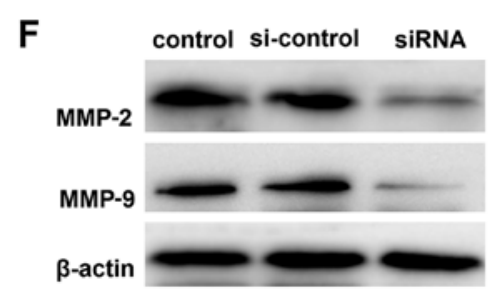

Figure 8. Effect of PGAM1 siRNA knockdown on cell movement ability. (A-C) Migration and invasion ability of U87 cells. (F) Western blot analysis of the protein levels of MMP2 (D) and MMP9 (E). Scale bar, $200 \mu \mathrm{m}$. Data are mean \pm SD of 3 independent experiments $\left({ }^{* * *} \mathrm{P}<0.001\right.$ compared with si-control).

PGAM1 was associated with poor survival of patients with lung adenocarcinoma (5). Another study suggested that overexpression of PGAM1 was strongly correlated with poor differentiation and decreased survival rates in hepatocellular carcinoma (7). A recent study also demonstrated that PGAM1 knockdown had a marked survival benefit in mice with intracranial xenografts (38). These studies suggest that PGAM1 probably participates in gliomagenesis. Our results show that PGAM1 expression was significantly upregulated in glioma tissues compared with human brain tissues. Furthermore, PGAM1 expression increased with increasing pathological glioma grade. Our result is consistent with a recent report of protein expression profiles in gliomas (39). Taken together, these results indicate that PGAM1 might function as a tumor promoter in glioma.

We confirmed the function of PGAM1 in glioma cells. MTT assay showed that cell proliferation was inhibited with transfection of PGAM1 siRNA into U87 cells. Moreover, siRNA knockdown of PGAM1 expression significantly induced glioma cell apoptosis in vitro by upregulating Bax expression, downregulating $\mathrm{Bcl}-2$ expression, and activating the caspase- 3 signal in glioma cells. In addition, siRNA 
knockdown of PGAM1 induced S-phase cell cycle arrest and decreased the rate of cells in the $\mathrm{G} 2 / \mathrm{M}$ phase in U87 cells. The highly invasive nature of glioma cells renders them incurable by localized therapy including surgery and radiotherapy, thereby leading to poor patient survival $(40,41)$. Thus, using RNA interference, we defined a specific role for PGAM1 in glioma migration and invasion. After transfection with PGAM1 siRNA for $48 \mathrm{~h}$, the rates of cell migration and invasion were significantly reduced compared with those in control cells, which suggests that PGAM1 knockdown is deleterious for U87 cell migration and invasion. Importantly, PGAM1 knockdown suppressed the protein levels of MMP2/9, markers for cell invasion, which may be important for inhibiting the invasive potential of U87 cells. Our data strongly suggest that PGAM1 plays an important role in glioma development and progression. Additional molecular and functional studies of PGAM1 in glioma cells are needed.

In conclusion, previous studies suggest that targeting PGAM1 by siRNA or with a small molecule inhibitor PGMI004A attenuates cancer cell proliferation $(7,36)$. In agreement with these observations, we found that the expression of PGAM1 is important in glioma cell proliferation. PGAM1 knockdown efficiently inhibited glioma cell migration and invasion and induced cell cycle arrest and apotosis in vitro. PGAM1 might be a promising therapy in clinical treatment of glioma, which heavily relies on aerobic glycolysis.

\section{Acknowledgements}

The present study was supported by the Natural Scientific Foundation of China (no. 81141088), the Promotive Research Fund for Excellent Young and Middle-aged Scientists of Shandong Province (no. 2004BS02010), the Jinan Youth Technology Star Plan (20120137), the Shandong Excellent Youth Scientist Research Fund (BS2012YY022), and the Shandong University Innovation Fund (2012TS135). Thanks to Laura Smales for the English editing.

\section{References}

1. Furnari FB, Fenton T, Bachoo RM, Mukasa A, Stommel JM, Stegh A, Hahn WC, Ligon KL, Louis DN, Brennan C, et al: Malignant astrocytic glioma: Genetics, biology, and paths to treatment. Genes Dev 21: 2683-2710, 2007.

2. Ostrom QT, Gittleman H, Farah P, Ondracek A, Chen Y, Wolinsky Y, Stroup NE, Kruchko C and Barnholtz-Sloan JS CBTRUS statistical report: Primary brain and central nervous system tumors diagnosed in the United States in 2006-2010 Neuro Oncol 15 (Suppl 2): iil-ii56, 2013.

3. Sant M, Minicozzi P, Lagorio S, Børge Johannesen T, MarcosGragera R and Francisci S; EUROCARE Working Group: Survival of European patients with central nervous system tumors. Int J Cancer 131: 173-185, 2012.

4. Evans MJ, Saghatelian A, Sorensen EJ and Cravatt BF: Target discovery in small-molecule cell-based screens by in situ proteome reactivity profiling. Nat Biotechnol 23: 1303-1307, 2005.

5. Chen G, Gharib TG, Wang H, Huang CC, Kuick R, Thomas DG, Shedden KA, Misek DE, Taylor JM, Giordano TJ, et al: Protein profiles associated with survival in lung adenocarcinoma. Proc Natl Acad Sci USA 100: 13537-13542, 2003.

6. Narayanan NK, Narayanan BA and Nixon DW: Resveratrolinduced cell growth inhibition and apoptosis is associated with modulation of phosphoglycerate mutase B in human prostate cancer cells: Two-dimensional sodium dodecyl sulfatepolyacrylamide gel electrophoresis and mass spectrometry evaluation. Cancer Detect Prev 28: 443-452, 2004.
7. Ren F, Wu H, Lei Y, Zhang H, Liu R, Zhao Y, Chen X, Zeng D, Tong A, Chen L, et al: Quantitative proteomics identification of phosphoglycerate mutase 1 as a novel therapeutic target in hepatocellular carcinoma. Mol Cancer 9: 81, 2010.

8. Liu L, Wang S, Zhang Q and Ding Y: Identification of potential genes/proteins regulated by Tiam1 in colorectal cancer by microarray analysis and proteome analysis. Cell Biol Int 32: 1215-1222, 2008.

9. Turhani D, Krapfenbauer K, Thurnher D, Langen $H$ and Fountoulakis M: Identification of differentially expressed, tumor-associated proteins in oral squamous cell carcinoma by proteomic analysis. Electrophoresis 27: 1417-1423, 2006.

10. Fang MZ, Liu C, Song Y, Yang GY, Nie Y, Liao J, Zhao X, Shimada Y, Wang LD and Yang CS: Overexpression of gastrin-releasing peptide in human esophageal squamous cell carcinomas. Carcinogenesis 25: 865-871, 2004.

11. Tong A, Wu L, Lin Q, Lau QC, Zhao X, Li J, Chen P, Chen L, Tang H, Huang C, et al: Proteomic analysis of cellular protein alterations using a hepatitis B virus-producing cellular model. Proteomics 8: 2012-2023, 2008.

12. Zhang S, Zhao Y, Lei B, Li C and Mao X: PGAM1 is involved in spermatogenic dysfunction and affects cell proliferation, apoptosis, and migration. Reprod Sci 22: 1236-1242, 2015.

13. Engel M, Mazurek S, Eigenbrodt E and Welter C: Phosphoglycerate mutase-derived polypeptide inhibits glycolytic flux and induces cell growth arrest in tumor cell lines. J Biol Chem 279: 35803-35812, 2004.

14. Louis DN, Ohgaki H, Wiestler OD, Cavenee WK, Burger PC, Jouvet A, Scheithauer BW and Kleihues P: The 2007 WHO classification of tumours of the central nervous system (vol 114, pg 97, 2007). Acta Neuropathol 114: 547-547, 2007.

15. Wen PY and Kesari S: Malignant gliomas in adults. N Engl J Med 359: 492-507, 2008.

16. Weller M, van den Bent M, Hopkins K, Tonn JC, Stupp R, Falini A, Cohen-Jonathan-Moyal E, Frappaz D, Henriksson R, Balana C, et al; European Association for Neuro-Oncology (EANO) Task Force on Malignant Glioma: EANO guideline for the diagnosis and treatment of anaplastic gliomas and glioblastoma. Lancet Oncol 15: e395-e403, 2014.

17. Warburg O: On the origin of cancer cells. Science 123: 309-314, 1956.

18. Kroemer G and Pouyssegur J: Tumor cell metabolism: Cancer's Achilles' heel. Cancer Cell 13: 472-482, 2008.

19. Ortega AD, Sánchez-Aragó M, Giner-Sánchez D, SánchezCenizo L, Willers I and Cuezva JM: Glucose avidity of carcinomas. Cancer Lett 276: 125-135, 2009.

20. Moreno-Sánchez R, Rodríguez-Enríquez S, Marín-Hernández A and Saavedra E: Energy metabolism in tumor cells. FEBS J 274: 1393-1418, 2007.

21. Altenberg B and Greulich KO: Genes of glycolysis are ubiquitously overexpressed in 24 cancer classes. Genomics 84: 1014-1020, 2004.

22. Amann T, Maegdefrau U,Hartmann A,Agaimy A, Marienhagen J, Weiss TS, Stoeltzing O, Warnecke C, Schölmerich J, Oefner PJ, et al: GLUT1 expression is increased in hepatocellular carcinoma and promotes tumorigenesis. Am J Pathol 174: 1544-1552, 2009.

23. Meadows AL, Kong B, Berdichevsky M, Roy S, Rosiva R, Blanch HW and Clark DS: Metabolic and morphological differences between rapidly proliferating cancerous and normal breast epithelial cells. Biotechnol Prog 24: 334-341, 2008.

24. Ozbudak IH, Shilo K, Tavora F, Rassaei N, Chu WS, Fukuoka J, Jen J, Travis WD and Franks TJ: Glucose transporter-1 in pulmonary neuroendocrine carcinomas: Expression and survival analysis. Mod Pathol 22: 633-638, 2009.

25. Boag JM, Beesley AH, Firth MJ, Freitas JR, Ford J, Hoffmann K, Cummings AJ, de Klerk NH and Kees UR: Altered glucose metabolism in childhood pre-B acute lymphoblastic leukaemia. Leukemia 20: 1731-1737, 2006.

26. Mao P, Joshi K, Li J, Kim SH, Li P, Santana-Santos L, Luthra S, Chandran UR, Benos PV, Smith L, et al: Mesenchymal glioma stem cells are maintained by activated glycolytic metabolism involving aldehyde dehydrogenase 1A3. Proc Natl Acad Sci USA 110: 8644-8649, 2013.

27. Feichtinger RG, Weis S, Mayr JA, Zimmermann F, Geilberger R, Sperl W and Kofler B: Alterations of oxidative phosphorylation complexes in astrocytomas. Glia 62: 514-525, 2014.

28. Bögler O, Huang HJ, Kleihues $P$ and Cavenee WK: The p53 gene and its role in human brain tumors. Glia 15: 308-327, 1995.

29. Ma W, Sung HJ, Park JY, Matoba S and Hwang PM: A pivotal role for p53: Balancing aerobic respiration and glycolysis. J Bioenerg Biomembr 39: 243-246, 2007. 
30. Matoba S, Kang JG, Patino WD, Wragg A, Boehm M, Gavrilova O, Hurley PJ, Bunz F and Hwang PM: p53 regulates mitochondrial respiration. Science 312: 1650-1653, 2006.

31. Zhang H, Gao P, Fukuda R, Kumar G, Krishnamachary B, Zeller KI, Dang CV and Semenza GL: HIF-1 inhibits mitochondrial biogenesis and cellular respiration in VHL-deficient renal cell carcinoma by repression of C-MYC activity. Cancer Cell 11: 407-420, 2007.

32. Astuti D, Latif F, Dallol A, Dahia PL, Douglas F, George E, Sköldberg F, Husebye ES, Eng C and Maher ER: Gene mutations in the succinate dehydrogenase subunit SDHB cause susceptibility to familial pheochromocytoma and to familial paraganglioma. Am J Hum Genet 69: 49-54, 2001.

33. Pelicano H, Martin DS, Xu RH and Huang P: Glycolysis inhibition for anticancer treatment. Oncogene 25: 4633-4646, 2006.

34. Inoki K, Zhu T and Guan KL: TSC 2 mediates cellular energy response to control cell growth and survival. Cell 115: 577-590, 2003.

35. Grisolia S and Cleland WW: Influence of salt, substrate, and cofactor concentrations on the kinetic and mechanistic behavior of phosphoglycerate mutase. Biochemistry 7: 1115-1121, 1968.
36. Hitosugi T, Zhou L, Elf S, Fan J, Kang HB, Seo JH, Shan C, Dai Q, Zhang L, Xie J, et al: Phosphoglycerate mutase 1 coordinates glycolysis and biosynthesis to promote tumor growth. Cancer Cell 22: 585-600, 2012.

37. Hitosugi T, Zhou L, Fan J, Elf S, Zhang L, Xie J, Wang Y, Gu TL, Alečković M, LeRoy G, et al: Tyr26 phosphorylation of PGAM1 provides a metabolic advantage to tumours by stabilizing the active conformation. Nat Commun 4: 1790, 2013.

38. Sanzey M, Abdul Rahim SA, Oudin A, Dirkse A, Kaoma T, Vallar L, Herold-Mende C, Bjerkvig R, Golebiewska A, Niclou SP: Comprehensive analysis of glycolytic enzymes as therapeutic targets in the treatment of glioblastoma. PLoS One 10: 102015,2015

39. Gao H, Yu B, Yan Y, Shen J, Zhao S, Zhu J, Qin W and Gao Y: Correlation of expression levels of ANXA2, PGAM1, and CALR with glioma grade and prognosis. J Neurosurg 118: 846-853, 2013.

40. Louis DN: Molecular pathology of malignant gliomas. Annu Rev Pathol 1: 97-117, 2006.

41. Giese A, Bjerkvig R, Berens ME and Westphal M: Cost of migration: Invasion of malignant gliomas and implications for treatment. J Clin Oncol 21: 1624-1636, 2003. 